\title{
Safety study: is there a pathologic IGF-I, PDGF and TGF- $\beta$ cytokine expression caused by adjunct BMP-7 in tibial and femoral non-union therapy?
}

This article was published in the following Dove Press journal:

Therapeutics and Clinical Risk Management

\author{
Christian Fischer \\ Christian Reiner ${ }^{2}$ \\ Gerhard Schmidmaier' \\ Julian Doll' \\ Christopher Child ${ }^{3}$ \\ Paul Alfred Grützner ${ }^{4}$ \\ Bahram Biglari ${ }^{4}$ \\ Sonja Boxriker ${ }^{5}$ \\ Arash Moghaddam ${ }^{5}$ \\ 'Center for Orthopedics, Trauma \\ Surgery and Spinal Cord Injury, \\ HTRG - Heidelberg Trauma \\ Research Group, Heidelberg \\ University Hospital, Heidelberg, \\ Germany; ${ }^{2}$ Department of Trauma \\ and Orthopedic Surgery, Paracelsus \\ Medical University, Nuremberg \\ Hospital South, Nuremberg. \\ Germany; ${ }^{3}$ Department of Trauma \\ Surgery, University Hospital Zurich, \\ Zurich, Switzerland; ${ }^{4}$ Trauma and \\ Orthopedics, BG Trauma Center \\ Ludwigshafen, Ludwigshafen, Germany; \\ ${ }^{5}$ Center of Orthopedics, Trauma \\ Surgery and Sport Medicine, ATORG \\ Aschaffenburg-Alzenau, Aschaffenburg, \\ Germany
}

Correspondence: Christian Fischer

Center for Orthopedics, Trauma

Surgery and Spinal Cord Injury,

HTRG - Heidelberg Trauma Research

Group, Heidelberg University Hospital,

Schlierbacher Landstrasse 200a,

69118 Heidelberg, Germany

$\mathrm{Tel}+4962215635366$

Fax +49622I 5626264

Email christian.fischer@med.uni-

heidelberg.de
Background: In this prospective safety study, we investigated if the characteristic cytokine expression during bone regeneration is manipulated by the local application of bone morphogenetic protein-7 (BMP-7) in non-union surgery. Therefore, the levels of insulin like growth factor 1 (IGF-1), platelet-derived growth factor $\mathrm{AB}$ (PDGF-AB) and transforming growth factor beta (TGF- $\beta$ ) were compared between patients with the gold standard use of autologous bone graft (ABG) and those with additional application of BMP-7 as part of the diamond concept.

Patients and methods: Between 2009 and 2014, of the 153 patients with tibial and femoral non-unions, a matched pair analysis was performed to compare the serological cytokine expressions. Blood samples were collected preoperatively, 1, 2 and 6 weeks as well as 3 and 6 months after non-union surgery. Matching criteria were smoking status, fracture location, gender, age and body mass index (BMI). Patients in G1 $(n=10)$ were treated with ABG and local BMP-7 while their matching partners in $\mathrm{G} 2(\mathrm{n}=10)$ received ABG only. The routine clinical and radiologic follow-up was 1 year.

Results: Although the IGF-1 quantification in G2 showed higher pre- and postoperative values compared to $\mathrm{G} 1(p<0.05)$, the courses of both groups were similar. Likewise, PDGF-AB and TGF- $\beta$ expressions appeared similar in G1 and G2 with peaks in both groups at 2 weeks follow-up. Osseous consolidation was assessed in all operated non-unions. The adjunct application of BMP-7 did not cause any pathologic cytokine expression.

Conclusion: Similar expressions of the serum cytokines IGF-1, PDGF-AB and TGF- $\beta$ were demonstrated in non-union patients treated with ABG and additional application of BMP-7 according to the diamond concept. Our findings indicate that the local application of BMP-7, which imitates the physiologic secretion of growth factors during bone regeneration, is safe and without the risk of abnormal systemic cytokine expression. Studies with higher patient numbers will have to validate these assumptions.

Keywords: bone morphogenetic protein, cytokine, non-union, safety

\section{Introduction}

There are $10 \%$ of long bone fractures that do not heal and evolve non-unions. In patients at special risk, this rate can reach up to $30 \%{ }^{1,2}$ Multiple therapeutic options for the treatment of non-unions include debridement, implant replacement and transplantation of autologous bone grafts (ABGs) that contain mesenchymal stem cells (MSCs) ${ }^{3,4}$ and combine osteoinductive, osteoconductive and osteogenetic effects. ${ }^{5}$ The diamond concept, as an alternative non-union treatment concept, includes mechanical stability and additional use of growth factors like BMP-7 (Osigraft ${ }^{\circledR}$; Olympus Biotech Europe, Lyon, France) and matrix scaffolds, ${ }^{6,7}$ because a successful treatment depends on an 
optimal mechanical and biological environment. This holistic concept has been proven to be effective in the treatment of atrophic non-unions. ${ }^{8-10}$

Bone regeneration and fracture healing are influenced by growth factors and cytokines as has been reported before. ${ }^{1-15}$ Specifically, the insulin-like growth factor 1 (IGF-1), plateletderived growth factor AB (PDGF-AB) and the transforming growth factor beta (TGF- $\beta$ ) are cytokines that ensure physiologic osseous regeneration. ${ }^{16-20}$ IGF-1, which serves as a regulator during bone turnover, has autocrine functions inside the fracture callus and facilitates the proliferation and differentiation of osteoprogenitor cells. ${ }^{17,21-25}$ Low IGF-1 expressions have been demonstrated in non-union patients. ${ }^{22}$ PDGF-AB, which controls the inflammatory response, ${ }^{26,27}$ is released early during the fracture-healing cascade and promotes the revascularization at the fracture site. ${ }^{15,17,28,29}$ An increased concentration of PDGF-AB in patients' sera with regular bone healing as well as its positive effect on fracture healing has been proven, ${ }^{26,28}$ whereas lower PDGF-AB levels have been observed in patients with non-unions. ${ }^{20}$ TGF- $\beta$, as a substantial promoter for fracture healing and bone remodeling, ${ }^{30}$ plays a significant role in the early phases of bone metabolism. ${ }^{31}$ While stimulating the mobilization of bone marrow MSCs and osteoprogenitor cells, it is also a chemotactic promoter of osteogenic differentiation. ${ }^{14,17,32,33}$ Consequently, the promotion through TGF- $\beta$ leads to the formation of osteoblasts and eventually to new bone formation. ${ }^{11,30,34}$

Clinical studies have demonstrated the effect of additional BMP-7 to foster non-union consolidation. ${ }^{35}$ Recently, similar PDGF and TGF- $\beta$ expressions have been demonstrated in fracture patients with proper healing and in non-union patients treated with BMP-7. ${ }^{36}$ As non-union patients treated with BMP-7 show increased expression patterns for angiogenic and inflammable cytokines like IL- $6,{ }^{37}$ we wanted to analyze if this was also true for cytokines like IGF-1, PDGF-AB and TGF- $\beta$ whose disturbance is rated as carcinogenetic factor. ${ }^{38-41}$ Therefore, in this study, we applied a standardized long-term cytokine protocol which comprised blood samplings before and until 6 months after non-union revision surgery at six different points of time. Peripheral blood concentrations of IGF-1, PDGF-AB and TGF- $\beta$ were used as objective monitoring criteria on a molecular level to assess if the adjunct application of BMP-7 within the diamond concept $t^{6}$ causes pathologic stimulation of cytokines in comparison to the mere transplantation of $\mathrm{ABG} .^{3}$

Our hypothesis was that the administration of BMP-7 in non-union surgery is safe and does not disturb the physiological expression of IGF-1, PDGF-AB and TGF- $\beta$ during bone regeneration.

\section{Patients and methods}

\section{Patients}

This prospective, controlled study was conducted in accordance with the declaration of Helsinki, approved by both the ethics committee of the Ruprecht-Karls-University of Heidelberg (157/2002 and S-636/2011) and the ethics committee of the medical association Rheinland-Pfalz (837.422.12). Between 2009 and 2014, we registered 153 patients with tibial or femoral fracture non-unions who received revision surgery at one of the two participating primary trauma centers. All patients provided written informed consent to participate in this research. Inclusion criteria were the minimum age of 18 years, the presence of a fracture non-union, clinical and radiologic follow-up over at least 12 months (Figure 1) and the formal agreement with the study. Patients with a history of malignoma or inflammatory diseases as well as long-term use of immunosuppressive drugs were excluded.

Out of this non-union register, 20 patients were matched into pairs (Figure 2): 10 patients received $A B G$ plus BMP-7 (G1) and 10 patients received ABG transplantation alone (G2). Specific matching criteria were "smoking", as it is known for its impact on bone healing, ${ }^{1}$ fracture location (tibia or femur) and gender. Subordinated criteria in our matched pair analysis were age and body mass index
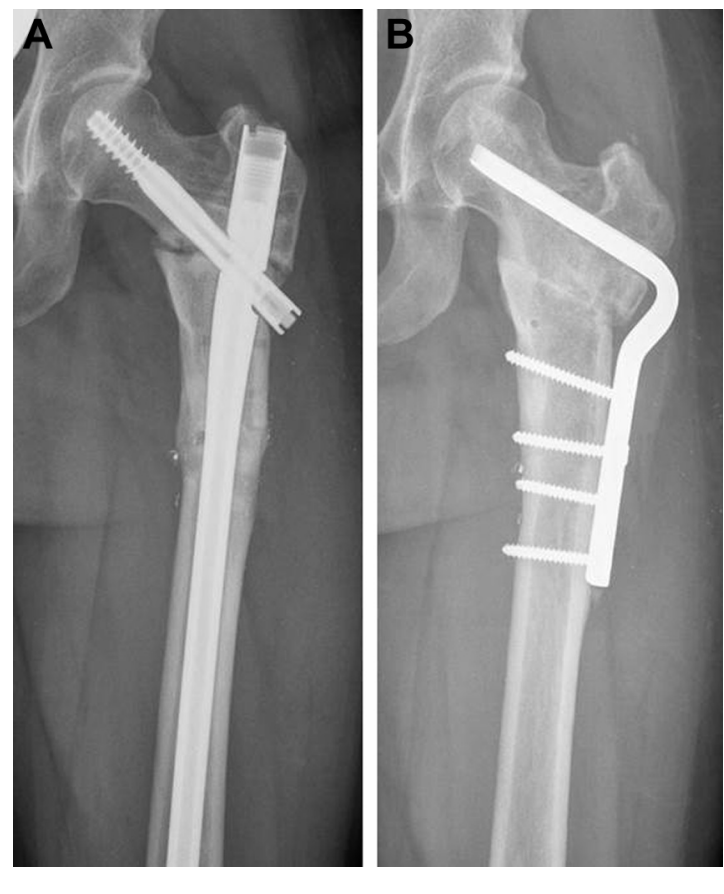

Figure I Perioperative $X$-rays of a femoral non-union.

Notes: Before non-union treatment according to the diamond concept $(\mathbf{A})$ and 6 months postoperatively when consolidation was achieved (B). The intramedullary nail was removed, the non-union resected and the gap was filled with $A B G$ (autologous bone graft), $3.3 \mathrm{mg}$ BMP-7 and a tricalcium phosphate bone graft (Vitoss; Stryker, Duisburg, Germany). Re-osteosynthesis was performed with an angled blade plate. 

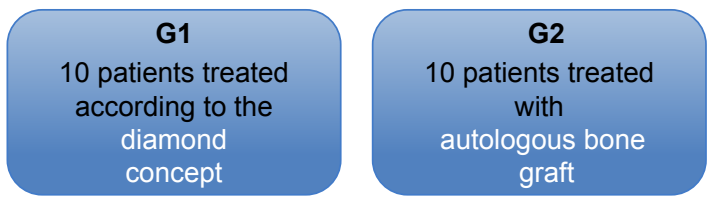

Figure 2 Groups of matched patients: GI - treatment with BMP-7 and autologous bone graft $(A B G)$ according to the diamond concept, $G 2$ - treatment with ABG alone.

(BMI). The patients' smoking status was defined by their cotinine status and a questionnaire. The cotinine status was measured according to the standardized procedure of the manufacturer (Cotinine Direct ELISA Kit; Nal Von Minden, Maarn, the Netherlands).

G1 group included 10 patients (seven females, three males) with a mean age of 48.8 years and an average BMI of $29.1 \mathrm{~kg} / \mathrm{m}^{2}$ (range, $20.3-41.8 \mathrm{~kg} / \mathrm{m}^{2}$ ). Five patients were declared to be smokers and tested positive for cotinine. G2 group contained 10 patients (seven females, three males) with a mean age of 49.4 years and a mean BMI of $25.6 \mathrm{~kg} / \mathrm{m}^{2}$ (range, 18 to $39.5 \mathrm{~kg} / \mathrm{m}^{2}$ ). Four patients were tested positive for cotinine (Table 1).

\section{Sample acquisition}

The cytokine expressions of IGF-1, PDGF-AB and TGF- $\beta$ were analyzed according to an established cytokine protocol (Figure 3) in blood samples collected preoperatively, 1, 2 and 6 weeks as well as 3 and 6 months after surgery (S-Monovette $7.5 \mathrm{~mL}$ serum tubes; Sarstedt AG, Nümbrecht, Germany).
The preoperative value was needed to establish an initial group-specific level before any interference by surgery. The samples were centrifuged at 3,000 rpm for 10 minutes at a temperature of $15^{\circ} \mathrm{C}$. Afterward, the supernatant obtained from the serum samples was removed and pipetted into Eppendorf tubes before being stored at $-80^{\circ} \mathrm{C}$.

For the analysis, the tubes were defrosted and brought to room temperature. We used commercially available ELISA kits to measure IGF-1, PDGF-AB and TGF- $\beta$ according to the manufacturer's recommendation (Quantikine $^{\odot}$ ELISA Kits; R\&D Systems, Minneapolis, MN, USA). Each sample was measured twice to avoid incidental findings.

\section{Surgical procedure}

After implant removal, debridement and re-osteosynthesis, we used ABG mixed with $3.3 \mathrm{mg}$ BMP-7 (G1) and ABG only (G2) to fill the non-union gap. The ABG was generated via reamer irrigator aspirator (RIA) technique from the opposite femur $^{42,43}$ or harvested from the iliac crest.

\section{Data analysis}

Due to the abnormal distribution of the data, nonparametric tests were used to compare samples. Statistical analysis for independent variables (different groups) was realized with the Mann-Whitney $U$-test, and dependent variables (within one group) were compared with the Wilcoxon's signed-rank test. The serum levels of the analyzed cytokines at different points

Table I Characteristics of study patients who were matched into pairs

\begin{tabular}{|c|c|c|c|c|c|c|c|}
\hline Code & Gender & $\begin{array}{l}\text { Age } \\
\text { (years) }\end{array}$ & Location & $\begin{array}{l}\text { BMI } \\
\left(\mathrm{kg} / \mathrm{m}^{2}\right)\end{array}$ & Smoker & $\begin{array}{l}\text { Cotinine } \\
\text { status }\end{array}$ & Procedure \\
\hline G002 & $\mathrm{F}$ & 56 & Tibia & 29.06 & NS & Neg & Diamond \\
\hline G020 & $\mathrm{F}$ & 54 & Tibia & 23.43 & FS & Neg & $A B G$ \\
\hline G019 & M & 41 & Tibia & 41.8 & $\mathrm{~S}$ & Pos & Diamond \\
\hline 268DKT & $M$ & 39 & Tibia & 25.7 & $\mathrm{~S}$ & Pos & $A B G$ \\
\hline G018 & $\mathrm{F}$ & 41 & Tibia & 40.1 & NS & Neg & Diamond \\
\hline $26 I P C$ & $\mathrm{~F}$ & 24 & Tibia & 18 & NS & Neg & $\mathrm{ABG}$ \\
\hline G029 & $\mathrm{F}$ & 58 & Tibia & 27.11 & NS & Neg & Diamond \\
\hline $263 R J$ & $\mathrm{~F}$ & 60 & Tibia & 29.23 & NS & Neg & $A B G$ \\
\hline G024 & $\mathrm{F}$ & 65 & Tibia & 21.72 & $\mathrm{~S}$ & Pos & Diamond \\
\hline 259GK & $\mathrm{F}$ & 70 & Tibia & 24.8 & $\mathrm{~S}$ & Pos & $A B G$ \\
\hline G005 & M & 52 & Tibia & 30.68 & FS & Pos & Diamond \\
\hline 283DW & M & 49 & Tibia & 22.2 & $\mathrm{~S}$ & Pos & $A B G$ \\
\hline G00I & $\mathrm{F}$ & 45 & Femur & 25.71 & NS & Neg & Diamond \\
\hline $\mathrm{COI7}$ & $\mathrm{F}$ & 46 & Femur & 27.06 & FS & Neg & $\mathrm{ABG}$ \\
\hline G003 & $M$ & 46 & Femur & 32.87 & NS & Neg & Diamond \\
\hline 279RP & M & 69 & Femur & 39.5 & NS & Neg & $A B G$ \\
\hline G0I2 & $\mathrm{F}$ & 57 & Femur & 21.48 & $\mathrm{~S}$ & Pos & Diamond \\
\hline C008 & $\mathrm{F}$ & 41 & Femur & 21.55 & FS & Pos & $A B G$ \\
\hline G008 & $F$ & 27 & Femur & 20.32 & $S$ & Pos & Diamond \\
\hline $273 J Z$ & $F$ & 42 & Femur & 24.2 & $S$ & Pos & $\mathrm{ABG}$ \\
\hline
\end{tabular}

Abbreviations: F, female; M, male; S, smoker; NS, non-smoker; FS, former smoker; ABG, autologous bone graft; Neg, negative; Pos, positive. 


\section{Pre-} Pre-
operative

\section{1 week 2 weeks}

6 weeks
3 months 3 months 6 months were created with Sigmaplot software (Systat Software Inc., San Jose, CA, USA).

\section{Results}

The specific characteristics of the matched patients in G1 and G2 groups are summarized in Table 1. All operated non-unions showed eventual consolidation at 12 months follow-up. The group-specific cytokine expressions were as follows:

\section{IGF-I}

The course of IGF-1 expression was similar in both G1 and G2 groups, with higher levels in the G2 group throughout the entire period (Figure 4A). In G1 group, the mean
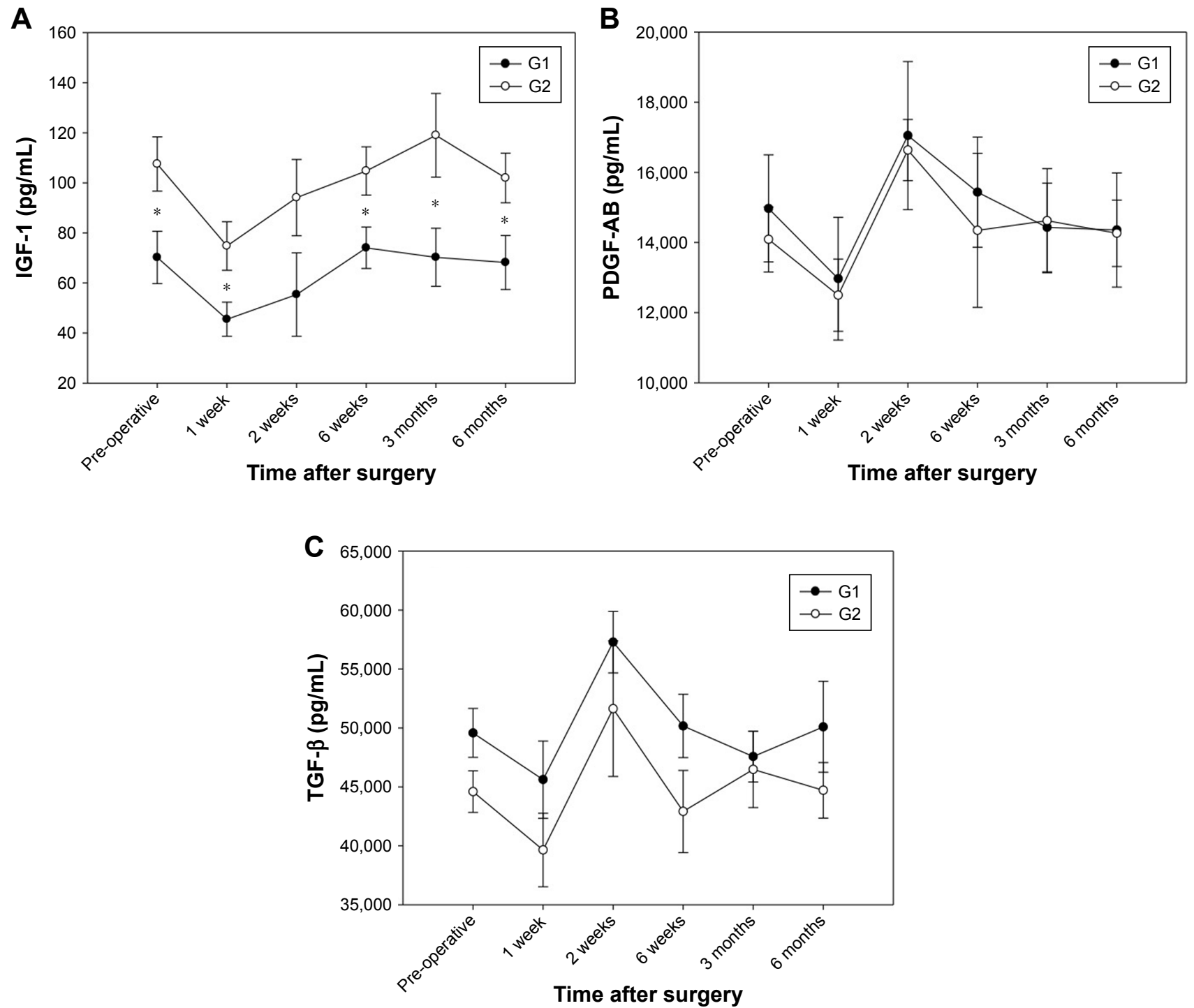

Figure 4 Analysis of sequential IGF-I (A), PDGF-AB (B) and TGF- $\beta$ (C) expression levels of GI (autologous bone graft with additional BMP-7) and G2 (autologous bone graft alone) groups expressed as absolute mean concentrations \pm standard deviation.

Notes: Serum concentration was measured in picograms per milliliter $(\mathrm{pg} / \mathrm{mL})$. The Wilcoxon's signed-rank test assessed significant differences between both groups at each particular time point (*indicates significant differences, $p<0.05$ ). 
concentration dropped from $70.2 \mathrm{pg} / \mathrm{mL}$ preoperatively to $45.5 \mathrm{pg} / \mathrm{mL}$ at 1 week, followed by a significant increase to its maximum at 6 weeks $(74.1 \mathrm{pg} / \mathrm{mL} ; p=0.037)$. At 6 months, the level was still significantly higher than at 1 week $(p=0.038)$. In $\mathrm{G} 2$ group, the mean concentration dropped from $107.6 \mathrm{pg} / \mathrm{mL}$ preoperatively to $74.8 \mathrm{pg} / \mathrm{mL}$ at 1 week, followed by a significant increase to its maximum at 3 months $(119.0 \mathrm{pg} / \mathrm{mL})$. At 6 months, the level was still significantly higher than at 1 week $(p=0.021)$.

\section{PDGF-AB}

The mean concentrations in both the groups were almost equivalent over the entire period (Figure 4B). In G1 group, the mean concentration dropped from $14,973.0 \mathrm{pg} / \mathrm{mL}$ preoperatively to $12,968.9 \mathrm{pg} / \mathrm{mL}$ at 1 week, followed by an increase to a maximum at 2 weeks $(17,051.4 \mathrm{pg} / \mathrm{mL})$. From this point, it slowly declined to the 6-month level $(14,357.3 \mathrm{pg} / \mathrm{mL})$. In G2 group, the mean concentration dropped from $14,088.3 \mathrm{pg} / \mathrm{mL}$ preoperatively to $12,496.7 \mathrm{pg} / \mathrm{mL}$ at 1 week, followed by an increase to a maximum at 2 weeks $(16,637.5 \mathrm{pg} / \mathrm{mL})$. From this point, it declined to the 6-month level $(14,263.2 \mathrm{pg} / \mathrm{mL})$.

\section{TGF- $\beta$}

As before, G1 and G2 groups demonstrated almost equivalent expressions over the monitoring period with consistently higher levels in G1 group (Figure 4C). In G1 group, the mean concentration dropped from 49,580.4 pg/mL preoperatively to $45,609.8 \mathrm{pg} / \mathrm{mL}$ at 1 week, followed by an increase to a maximum at 2 weeks $(57,281.1 \mathrm{pg} / \mathrm{mL})$. After further decline until 6 weeks $(50,169.56 \mathrm{pg} / \mathrm{mL})$, the course of the TGF- $\beta$ levels remained almost constant. In G2 group, the mean concentration dropped from 44,591.1 pg/mL preoperatively to $39,644.4 \mathrm{pg} / \mathrm{mL}$ at 1 week, followed by an increase to a maximum at 2 weeks $(51,633.3 \mathrm{pg} / \mathrm{mL})$. From this point, it declined to the 6 -week level $(42,908.6 \mathrm{pg} / \mathrm{mL})$ followed by a slight increase at 3 months $(46,475.6 \mathrm{pg} / \mathrm{mL})$, and the concentration remained almost steady thereafter.

\section{Discussion}

The aim of this prospective safety study was to evaluate the biological impact of additional BMP-7 administration in non-union therapy on a molecular level comparing the growth factor expression levels of IGF-1, PDGF-AB and TGF- $\beta$ to those of patients with $A B G$ alone as gold standard. The selection of IGF-1, PDGF-AB and TGF- $\beta$ for this study was based on their importance in bone regeneration and coincidental expression in cancer patients. ${ }^{38-41}$ Our results showed uniform courses of all three serum cytokines in G1 and G2 groups at different stages of the postoperative follow-up period. None of the measured cytokines demonstrated any pathologic reaction to the treatment with BMP-7 according to the diamond concept.

Interestingly, IGF-1 levels were lower in G1 than in G2 group throughout the entire measurements; however, the exact reason for this difference remains unclear. Based on the sequential measurements that included the preoperative IGF-1 expression levels, this difference is unlikely to be caused by the index surgery. The postoperative expression of IGF-1 with an explicit and steady rise after 1 week until 6 weeks in G1 and 12 weeks in G2 groups could equally be demonstrated in our preliminary studies, ${ }^{23,44}$ and high concentrations were also detected during fracture callus formation. ${ }^{22}$ The absolute values of PDGF-AB were almost identical in G1 and G2 groups. The steep increase to its 2-week maximum after an initial decrease can especially be traced back to the effect of PDGF-AB on the early phases of fracture healing. ${ }^{29}$ In preliminary studies, high PDGF-AB concentrations have been shown in patients with regular fracture healing as well as after successful non-union therapy. ${ }^{26,44}$ Similarly, almost no differences regarding the expression of TGF- $\beta$ could be noticed between the two study groups with one peak after 2 weeks. Preliminary studies confirmed this typical increase of TGF- $\beta$ at an early stage of fracture healing which could also be found for PDGF-AB. Certain "co-regulation functions" of these two cytokines could play a role. ${ }^{23}$

The treatment of a non-union with growth factors like BMP-7 is an important part of the diamond concept. ${ }^{6}$ Its osteoinductive effect as well as the increased bone healing has been described in former studies. ${ }^{5}$ In addition to that, the results of our previous studies showed that local application of BMP-7 leads to a cytokine expression pattern similar to that of patients with proper bone healing. ${ }^{36,44}$ Since the application of both BMP-7 and ABG is helpful for bone healing, a combined treatment is successfully used for the therapy of atrophic non-unions. ${ }^{45,46}$ Yet, the safety of additional BMP-7 administration has never been assured on a molecular level comparing the cytokine expressions to an equivalent group that has received $\mathrm{ABG}$ alone. The high costs of BMP-7 can only be justified if the known beneficial effects are not overshadowed by pathologic growth factor expressions whose consequences are not fully understood yet. The use of cytokine expression analyses based on our standardized study protocol allows not only to decode the underlying mechanisms of successful bone regeneration but 
also to analyze the potential harm of additional osteogenic proteins on a molecular level.

\section{Limitations}

One limitation of this study is the low number of included patients in spite of the specialization in non-union treatment at our institution. However, this is partially due to the classification of patients into pairs and the strict matching criteria applied. Still, a perfect matching, especially, with regard to the patients' age was not possible because of the heterogeneity of non-unions and their low incidence in clinical practice. Another limitation may arise from the differences in the age of samples as they were collected throughout the entire study period but analyzed at once, which could influence the cytokine concentrations.

\section{Strengths}

Advantages of this study are its cross-sectional design, standardized study protocol with strict clinical and radiologic follow-ups, clearly defined dates for the acquisition of blood samples and selection of patients according to specific matching criteria. Eventual radiologic and clinical consolidation of the operated non-unions could be ascertained in both study groups. The chronologic sequence of the cytokine measurements represents a reliable basis for the comparison of two treatment concepts. Our results assume that, with serum cytokine expression analysis, the safety of growth factor-based non-union treatment can be evaluated even with a small number of patients.

\section{Conclusion}

In this study, we could confirm the molecular safety of additional BMP-7 administration in non-union treatment within the diamond concept compared to a classic application of ABG by measuring the serum cytokines IGF-1, PDGF-AB and TGF- $\beta$. With the help of the serum cytokines, we conclude that the diamond concept is comparable to a therapy with $\mathrm{ABG}$ and without pathologic systemic expression of cytokines. With this established study protocol, the expression analysis of serum cytokines can be confirmed as a helpful method even with a low number of included patients. Yet, these findings have to be ascertained in studies with higher patient numbers.

\section{Acknowledgments}

The authors have revealed all financial and personal relationships to other persons and organizations that could inappropriately influence (bias) this work. We acknowledge the financial support of the Ruprecht-Karls-University of Heidelberg within the funding program Open Access Publishing.

\section{Disclosure}

GS is a consultant for Synthes (West Chester, PA, USA). The authors report no other conflicts of interest in this work.

\section{References}

1. Moghaddam A, Weiss S, Wölfl CG, et al. Cigarette smoking decreases TGF- $\beta 1$ serum concentrations after long bone fracture. Injury. 2010; 41(10):1020-1025.

2. Moghaddam A, Muller U, Roth HJ, Wentzensen A, Grutzner PA, Zimmermann G. TRACP $5 \mathrm{~b}$ and CTX as osteological markers of delayed fracture healing. Injury. 2011;42(8):758-764.

3. Fayaz HC, Giannoudis PV, Vrahas MS, et al. The role of stem cells in fracture healing and nonunion. Int Orthop. 2011;35(11):1587-1597.

4. Sen MK, Miclau T. Autologous iliac crest bone graft: should it still be the gold standard for treating nonunions? Injury. 2007;38 (Suppl 1): S75-S80.

5. Giannoudis PV. Fracture healing and bone regeneration: autologous bone grafting or BMPs? Injury. 2009;40(12):1243-1244.

6. Giannoudis PV, Einhorn TA, Marsh D. Fracture healing: the diamond concept. Injury. 2007;38 (Suppl 4):S3-S6.

7. Giannoudis PV, Einhorn TA, Schmidmaier G, Marsh D. The diamond concept - open questions. Injury. 2008;39 (Suppl 2):S5-S8.

8. Moghaddam A, Zietzschmann S, Bruckner T, Schmidmaier G. Treatment of atrophic tibia non-unions according to "diamond concept": Results of one- and two-step treatment. Injury. 2015;46 (Suppl 4): S39-S50.

9. Giannoudis PV, Gudipati S, Harwood P, Kanakaris NK. Long bone nonunions treated with the diamond concept: a case series of 64 patients. Injury. 2015;46 (Suppl 8):S48-S54.

10. Miska M, Findeisen S, Tanner M, et al. Treatment of nonunions in fractures of the humeral shaft according to the diamond concept. Bone Joint J. 2016;98-B(1):81-87.

11. Dimitriou R, Tsiridis E, Giannoudis PV. Current concepts of molecular aspects of bone healing. Injury. 2005;36(12):1392-1404.

12. Einhorn TA. The cell and molecular biology of fracture healing. Clin Orthop Relat Res. 1998;(355 Suppl):S7-S21.

13. Dimitriou R, Jones E, McGonagle D, Giannoudis PV. Bone regeneration: current concepts and future directions. BMC Med. 2011;9:66.

14. Tsiridis E, Upadhyay N, Giannoudis P. Molecular aspects of fracture healing: which are the important molecules? Injury. 2007;38 (Suppl 1): S11-S25.

15. Devescovi V, Leonardi E, Ciapetti G, Cenni E. Growth factors in bone repair. La Chirurgia degli organi di movimento. 2008;92(3): 161-168.

16. Deschaseaux F, Sensebe L, Heymann D. Mechanisms of bone repair and regeneration. Trends Mol Med. 2009;15(9):417-429.

17. Phillips AM. Overview of the fracture healing cascade. Injury. 2005; 36(Suppl 3):S5-S7.

18. Lieberman JR, Daluiski A, Einhorn TA. The role of growth factors in the repair of bone. Biology and clinical applications. J Bone Joint Surg Am. 2002;84-A(6):1032-1044.

19. Westerhuis RJ, van Bezooijen RL, Kloen P. Use of bone morphogenetic proteins in traumatology. Injury. 2005;36(12):1405-1412.

20. Schwabe P, Simon P, Kronbach Z, Schmidmaier G, Wildemann B. A pilot study investigating the histology and growth factor content of human non-union tissue. Int Orthop. 2014;38(12):2623-2629.

21. Schmidmaier G, Wildemann B, Ostapowicz D, et al. Long-term effects of local growth factor (IGF-I and TGF-beta 1) treatment on fracture healing. A safety study for using growth factors. J Orthop Res. 2004; 22(3):514-519. 
22. Weiss S, Henle P, Bidlingmaier M, Moghaddam A, Kasten P, Zimmermann G. Systemic response of the GH/IGF-I axis in timely versus delayed fracture healing. Growth Horm IGF Res. 2008;18(3): 205-212.

23. Fischer C, Doll J, Tanner M, et al. Quantification of TGF-ss1, PDGF and IGF-1 cytokine expression after fracture treatment vs non-union therapy via masquelet. Injury. 2016;47(2):342-349.

24. Sheng MH, Lau KH, Baylink DJ. Role of osteocyte-derived insulin-like growth factor I in developmental growth, modeling, remodeling, and regeneration of the bone. J Bone Metab. 2014;21(1):41-54.

25. Zhao G, Monier-Faugere MC, Langub MC, et al. Targeted overexpression of insulin-like growth factor I to osteoblasts of transgenic mice: increased trabecular bone volume without increased osteoblast proliferation. Endocrinology. 2000;141(7):2674-2682.

26. Weiss S, Zimmermann G, Pufe T, Varoga D, Henle P. The systemic angiogenic response during bone healing. Arch Orthop Trauma Surg. 2009;129(7):989-997.

27. Tzeng DY, Deuel TF, Huang JS, Senior RM, Boxer LA, Baehner RL. Platelet-derived growth factor promotes polymorphonuclear leukocyte activation. Blood. 1984;64(5):1123-1128.

28. Andrew JG, Hoyland JA, Freemont AJ, Marsh DR. Platelet-derived growth factor expression in normally healing human fractures. Bone. 1995;16(4):455-460.

29. Caplan AI, Correa D. PDGF in bone formation and regeneration: new insights into a novel mechanism involving MSCs. J Orthop Res. 2011; 29(12):1795-1803.

30. Joyce ME, Roberts AB, Sporn MB, Bolander ME. Transforming growth factor-beta and the initiation of chondrogenesis and osteogenesis in the rat femur. J Cell Biol. 1990;110(6):2195-2207.

31. Hering $\mathrm{S}$, Isken $\mathrm{E}$, Knabbe $\mathrm{C}$, et al. TGFbeta1 and TGFbeta2 mRNA and protein expression in human bone samples. Exp Clin Endocrinol Diabetes. 2001;109(4):217-226.

32. Zhao L, Jiang S, Hantash BM. Transforming growth factor beta1 induces osteogenic differentiation of murine bone marrow stromal cells. Tissue Eng Part A. 2010;16(2):725-733.

33. Wan M, Li C, Zhen G, et al. Injury-activated transforming growth factor beta controls mobilization of mesenchymal stem cells for tissue remodeling. Stem Cells. 2012;30(11):2498-2511.

34. Tang Y, Wu X, Lei W, et al. TGF-betal-induced migration of bone mesenchymal stem cells couples bone resorption with formation. Nature Med. 2009;15(7):757-765.

35. Zimmermann G, Muller U, Loffler C, Wentzensen A, Moghaddam A. Therapieerfolg bei atrophen Tibiaschaftpseudarthrosen. [Therapeutic outcome in tibial pseudarthrosis: bone morphogenetic protein 7 (BMP-7) versus autologous bone grafting for tibial fractures]. Der Unfallchirurg. 2007;110(11):931-938. German.
36. Moghaddam A, Breier L, Haubruck P, et al. Non-unions treated with bone morphogenic protein 7 : introducing the quantitative measurement of human serum cytokine levels as promising tool in evaluation of adjunct non-union therapy. J Inflamm (Lond). 2016;13:3.

37. Haubruck P, Kammerer A, Korff S, et al. The treatment of nonunions with application of BMP-7 increases the expression pattern for angiogenic and inflammable cytokines: a matched pair analysis. $J$ Inflamm Res. 2016;9:155-165.

38. Chen J, Ye L, Xie F, Yang Y, Zhang L, Jiang WG. Expression of bone morphogenetic protein 7 in lung cancer and its biological impact on lung cancer cells. Anticancer Res. 2010;30(4):1113-1120.

39. Gulei D, Mehterov N, Ling H, Stanta G, Braicu C, Berindan-Neagoe I. The "good-cop bad-cop" TGF-beta role in breast cancer modulated by non-coding RNAs. Biochimica et Biophysica Acta. 2017;1861(7): 1661-1675.

40. ter Braak B, Siezen C, Speksnijder EN, et al. Mammary gland tumor promotion by chronic administration of IGF1 and the insulin analogue AspB10 in the p53R270H/(+)WAPCre mouse model. Breast Cancer Res. 2015;17:14

41. Wu J, Zhu AX. Targeting insulin-like growth factor axis in hepatocellular carcinoma. J Hematol Oncol. 2011;4:30.

42. Kobbe P, Tarkin IS, Pape HC. Use of the "reamer irrigator aspirator" system for non-infected tibial non-union after failed iliac crest grafting. Injury. 2008;39(7):796-800.

43. Kuehlfluck P, Moghaddam A, Helbig L, et al. RIA fractions contain mesenchymal stroma cells with high osteogenic potency. Injury. 2015; 46 (Suppl 8):S23-S32.

44. Westhauser F, Zimmermann G, Moghaddam S, et al. Reaming in treatment of non-unions in long bones: cytokine expression course as a tool for evaluation of non-union therapy. Arch Orthop Trauma Surg. 2015; 135(8):1107-1116.

45. Giannoudis PV, Kanakaris NK, Dimitriou R, Gill I, Kolimarala V, Montgomery RJ. The synergistic effect of autograft and BMP-7 in the treatment of atrophic nonunions. Clin Orthop Rel Res. 2009;467(12) 3239-3248.

46. Moghaddam-Alvandi A, Zimmermann G, Buchler A, et al. Ergebnisse der Pseudarthrosenbehandlung mit "bone morphogenetic protein 7' (BMP-7). [Results of nonunion treatment with bone morphogenetic protein 7 (BMP-7)]. Der Unfallchirurg. 2012;115(6):518-526. German.
Therapeutics and Clinical Risk Management

\section{Publish your work in this journal}

Therapeutics and Clinical Risk Management is an international, peerreviewed journal of clinical therapeutics and risk management, focusing on concise rapid reporting of clinical studies in all therapeutic areas outcomes, safety, and programs for the effective, safe, and sustained use of medicines. This journal is indexed on PubMed Central, CAS,

\section{Dovepress}

EMBase, Scopus and the Elsevier Bibliographic databases. The manuscript management system is completely online and includes a very quick and fair peer-review system, which is all easy to use. Visit http://www.dovepress.com/testimonials.php to read real quotes from published authors. 